\title{
Assessment of pulmonary mechanics in mechanical ventilation
}

\author{
Federico Gordo ${ }^{1,2}$ and Beatriz Lobo-Valbuena ${ }^{1 *}$ (D) \\ See related research by Chen et al. https://ccforum.biomedcentral.com/articles/10.1186/s13054-017-1671-8
}

We read with great interest the article published by Chen et al. [1] regarding a systematic assessment of respiratory mechanics in patients with ARDS to determine ventilation parameters and the optimal mode. They used basic monitoring along with the placement of an esophageal balloon catheter to measure transpulmonary pressure. We believe that monitoring pulmonary mechanics may be useful, not only in these patients, but in the whole ICU population, allowing individualized ventilation. This may also be achieved by other advanced monitoring systems, such as electrical impedance tomography [2].

However, we fail to understand how the changes in PEEP cause changes in pulmonary recruitment and oxygenation without modifying-according to the authors-the physiological dead space.

Furthermore, the authors report how the monitoring of these patients led to changes in the mechanical ventilation mode, leading to a volume-controlled mode. Nonetheless, in their study they do not include the respiratory mechanics data on which they based these changes. In the discussion they refer to three factors-the control of the tidal volume (Vt), better monitoring of the pulmonary mechanics, and the possibility to place an inspiratory pause-that, in our opinion, are neither conclusive nor exclusive of the volume-controlled modes [3]. In fact, studies have suggested that better distribution of $\mathrm{Vt}$ can be achieved using pressure-controlled modes, generating a more homogenous ventilation and enabling an increase in the inspiratory time. Moreover, Villar et al. [4] have demonstrated less pulmonary damage using pressure-control ventilation modes, regardless of the selected Vt and PEEP.

\footnotetext{
* Correspondence: b.lobo.valbuena@gmail.com

${ }^{1}$ Intensive Care Unit, Hospital Universitario del Henares, Avenida María de Curie s/n, 28822 Coslada, Madrid, Spain

Full list of author information is available at the end of the article
}

We do believe that the generalization of systematic respiratory mechanics assessment is useful to improve ventilation in ARDS patients, but these procedures need to be standardized. Some authors argue that these tests do not take into account the heterogeneity of lung injury and prefer other approaches to adjust the ventilation of these patients [5].

\section{Abbreviations}

ARDS: Acute respiratory distress syndrome; ICU: Intensive care unit; PEEP: Positive end-expiratory pressure; Vt: Tidal volume

\section{Acknowledgements}

Not applicable.

Funding

No funding was required.

Availability of data and materials Not applicable.

\section{Authors' contributions}

FG and BLV helped on manuscript preparation and attest to the integrity of the data reported in the manuscript. Both authors read and approved the final manuscript.

\section{Competing interests}

The authors declare that they have no competing interests.

Consent for publication

Not applicable.

Ethics approval and consent to participate

Not applicable.

\section{Publisher's Note}

Springer Nature remains neutral with regard to jurisdictional claims in published maps and institutional affiliations.

\section{Author details}

${ }^{1}$ Intensive Care Unit, Hospital Universitario del Henares, Avenida María de Curie s/n, 28822 Coslada, Madrid, Spain. ${ }^{2}$ Universidad Francisco de Vitoria, Carretera Pozuelo a Majadahonda, 28223 Pozuelo de Alarcón, Madrid, Spain. 
Published online: 19 June 2017

\section{References}

1. Chen L, Chen GQ, Shore K, Shklar O, Martins C, Devenyi B, Lindsay P,

McPhail H, Lanys A, Soliman I, Tuma M, Kim M, Porretta K, Greco P, Every H,

Hayes C, Baker A, Friedrich JO, Brochard L. Implementing a bedside

assessment of respiratory mechanics in patients with acute respiratory distress syndrome. Crit Care. 2017;21(1):84.

2. Gordo F, Conejo I. What PEEP level should I use in my patient? Med Intensiva. 2017:41(5):267-9. doi:10.1016/j.medin.2016.10.010

3. Yoshida T, Nakahashi S, Nakamura MA, Koyama Y, Roldan R, Torsani V, De Santis RR, Gomes S, Uchiyama A, Amato MB, Kavanagh BP, Fujino Y. Volume controlled ventilation does not prevent injurious inflation during spontaneous effort. Am J Respir Crit Care Med. 2017. doi:10.1164/rccm. 201610-1972OC

4. Villar J, Martín-Rodríguez C, Domínguez-Berrot AM, Fernández L, Ferrando C, Soler JA, Díaz-Lamas AM, González-Higueras E, Nogales L, Ambrós A,

Carriedo D, Hernández M, Martínez D, Blanco J, Belda J, Parrilla D, SuárezSipmann F, Tarancón C, Mora-Ordoñez JM, Blanch L, Pérez-Méndez L, Fernández RL, Kacmarek RM, Spanish Initiative for Epidemiology, Stratification and Therapies for ARDS (SIESTA) Investigators Network. A quantile analysis of plateau and driving pressures: effects on mortality in patients with acute respiratory distress syndrome receiving lung-protective ventilation. Crit Care Med. 2017:45(5):843-50.

5. Amado-Rodríguez L, Del Busto C, García-Prieto E, Albaiceta GM. Mechanical ventilation in acute respiratory distress syndrome: The open lung revisited. Med Intensiva. 2017. doi:10.1016/j.medin.2016.12.012. 